\title{
Shu-Jing $\mathrm{Li}^{\star}$, Ke Li and Yi-Wen Li
}

\section{The crystal structure of 2-nitroisophthalic acid, $\mathrm{C}_{8} \mathrm{H}_{5} \mathrm{NO}_{6}$}

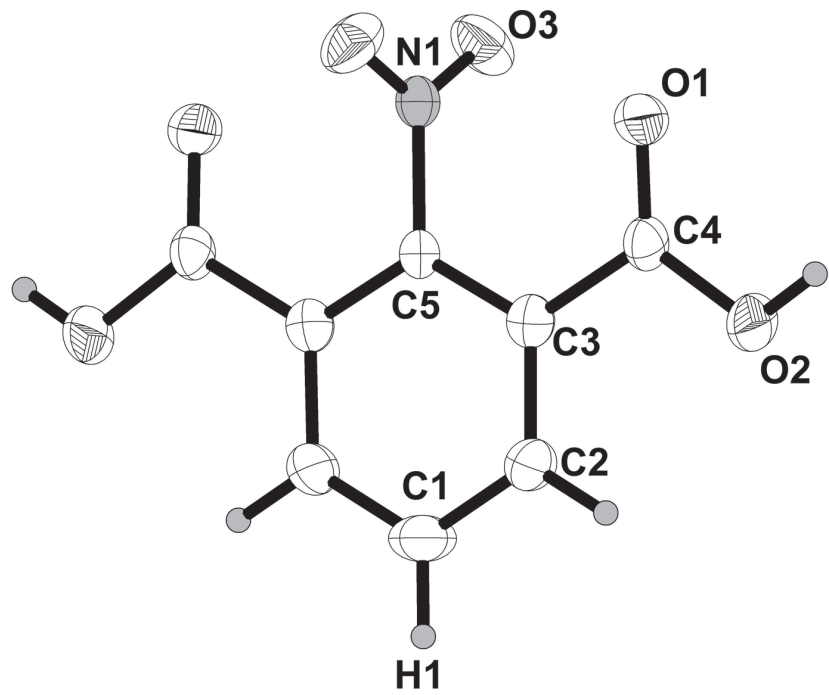

https://doi.org/10.1515/ncrs-2019-0704

Received September 18, 2019; accepted November 8, 2019; available online December 5, 2019

\begin{abstract}
$\mathrm{C}_{8} \mathrm{H}_{5} \mathrm{NO}_{6}$, monoclinic, $C 2 / c$ (no. 15), $\quad a=5.4755(12) \AA$, $b=14.377(3) \AA, \quad c=11.143(3) \AA, \quad \beta=99.096(9)^{\circ}$, $V=866.2(3) \AA^{3}, \quad Z=4, \quad R_{\mathrm{gt}}(F)=0.0455, \quad w R_{\mathrm{ref}}\left(F^{2}\right)=0.1341$, $T=150(2) \mathrm{K}$.
\end{abstract}

\section{CCDC no.: 1964554}

The molecular structure is shown in the figure (only the asymmetric unit is labelled). Table 1 contains crystallographic data and Table 2 contains the list of the atoms including atomic coordinates and displacement parameters.

\section{Source of material}

All of starting materials were purchased from commercial sources and used as received. The title compound was synthesized in THF solution: solid 2-nitroisophthalic acid (2.11 g,

*Corresponding author: Shu-Jing Li, Department of Chemistry and Chemical Engineering, Zhoukou Normal University, Zhoukou, Henan Province 466001, P.R. China, e-mail: zksylsj@163.com. https://orcid.org/0000-0002-5384-3402

Ke Li and Yi-Wen Li: Department of Chemistry and Chemical Engineering, Zhoukou Normal University, Zhoukou, Henan Province 466001, P.R. China

ð Open Access. @ 2019 Shu-Jing Li et al., published by De Gruyter. (c) BY License.
Table 1: Data collection and handling.

\begin{tabular}{ll}
\hline Crystal: & Colorless block \\
Size: & $0.35 \times 0.10 \times 0.07 \mathrm{~mm}$ \\
Wavelength: & Mo $K \alpha$ radiation $(0.71073 \AA)$ \\
$\mu:$ & $0.14 \mathrm{~mm}^{-1}$ \\
Diffractometer, scan mode: & Bruker APEX-II, $\varphi$ and $\omega$ \\
$\theta_{\text {max }}$, completeness: & $26.0^{\circ},>99 \%$ \\
$N(h k l)_{\text {measured }}, N(h k l)_{\text {unique }}, R_{\text {int }}:$ & $4377,857,0.060$ \\
Criterion for $I_{\text {obs }}, N\left(h k l_{\text {gt }}:\right.$ & $I_{\text {obs }}>2 \sigma\left(I_{\text {obs }}\right), 599$ \\
$N(\text { param })_{\text {refined }}:$ & 71 \\
Programs: & Bruker [1], SHELX [2], \\
& Olex2 [3, 4]
\end{tabular}

Table 2: Fractional atomic coordinates and isotropic or equivalent isotropic displacement parameters $\left(\AA^{2}\right)$.

\begin{tabular}{lrrrr}
\hline Atom & $\boldsymbol{x}$ & $\boldsymbol{y}$ & $\boldsymbol{z}$ & $\boldsymbol{U}_{\text {iso }} \boldsymbol{U}_{\text {eq }}$ \\
\hline $\mathrm{C} 1$ & 0.5 & $0.7574(2)$ & 0.25 & $0.0325(10)$ \\
$\mathrm{H} 1$ & 0.5 & $0.8234(2)$ & 0.25 & $0.0391(11)^{\star}$ \\
$\mathrm{C} 2$ & $0.3545(5)$ & $0.70918(16)$ & $0.3198(2)$ & $0.0246(6)$ \\
$\mathrm{H} 2$ & $0.2539(5)$ & $0.74270(16)$ & $0.3669(2)$ & $0.0295(7)^{\star}$ \\
$\mathrm{C} 3$ & $0.3534(4)$ & $0.61252(15)$ & $0.3221(2)$ & $0.0182(6)$ \\
$\mathrm{C} 4$ & $0.2000(4)$ & $0.56172(15)$ & $0.39952(19)$ & $0.0162(5)$ \\
$\mathrm{C} 5$ & 0.5 & $0.5658(2)$ & 0.25 & $0.0146(7)$ \\
$\mathrm{N} 1$ & 0.5 & $0.46333(17)$ & 0.25 & $0.0165(6)$ \\
01 & $0.2212(3)$ & $0.47870(10)$ & $0.42006(15)$ & $0.0223(5)$ \\
02 & $0.0421(3)$ & $0.61606(11)$ & $0.44293(15)$ & $0.0231(5)$ \\
H2a & $-0.042(3)$ & $0.5844(4)$ & $0.485(2)$ & $0.0346(7) *$ \\
03 & $0.3335(3)$ & $0.42440(11)$ & $0.18248(15)$ & $0.0250(5)$ \\
\hline
\end{tabular}

$0.01 \mathrm{~mol}$ ) was dissolved in $10 \mathrm{~mL}$ THF solution in a beaker equipped with a stirrer and stirred at room temperature for $5 \mathrm{~min}$. Then the solution was filtered and let evaporate slowly at room temperature in air. Colorless single crystals were obtained after 12 hours, yield: 93.4\% (based on 2-nitroisophthalic acid).

\section{Experimental details}

The structure was solved by direct methods with the SHELXS program. All $\mathrm{H}$-atoms from $\mathrm{C}$ atoms and $\mathrm{O}$ atoms were positioned with idealized geometry and refined isotropically $\left(U_{\text {iso }}(\mathrm{H})=1.2 U_{\text {eq }}(\mathrm{C})\right.$ or $\left.U_{\text {iso }}(\mathrm{H})=1.5 U_{\text {eq }}(\mathrm{O})\right)$ using a riding model with $\mathrm{C}-\mathrm{H}=0.95 \AA$ and $\mathrm{O}-\mathrm{H}=0.84 \AA$, respectively. 


\section{Comment}

Some 4- and 5-nitroisophthalic acids or their analogues have been reported [5-8]. However, no structural result have been reported for 2-nitroisophthalic acid or 2-nitroisophthalate. To the best of our knowledge, only one crystal strucure of an analogue of 2-nitroisophthalic acid, bis(2,2,2-trinitroethyl) 2, 4,6-trinitroisophthalate, has been reported elsewhere [9].

As shown in the figure, there is a two-fold axis along the direction of the line of $\mathrm{H} 1-\mathrm{C} 1-\mathrm{C} 5-\mathrm{N} 1$. All of the atoms except the two $\mathrm{O}$ atoms from the nitro group are co-planar. The plane defined by the three atoms of the nitro group is almost perpendicular to the plane of benzene ring $\left(\sim 96^{\circ}\right)$. There are hydrogen bonds: $\mathrm{O}-\mathrm{H} \cdots \mathrm{O}$ (carboxyl). The carboxyl groups are linked to generate one-dimensional chains by the strong $\mathrm{O}-\mathrm{H} \cdot \mathrm{*} \mathrm{O}$ (carboxyl)-type of hydrogen bond. All bond lengths and angles of the 2-nitroisophthalic acid are comparable to that reported in the literature [9].

\section{References}

1. Bruker. SAINT v8.37A. Bruker AXS Inc, Madison, WI, USA (2015).
2. Sheldrick, G. M.: A short history of SHELX. Acta Crystallogr. A64 (2008) 112-122.

3. Bourhis, L. J.; Dolomanov, O. V.; Gildea, R. J.; Howard, J. A. K.; Puschmann, H.: The anatomy of a comprehensive constrained, restrained refinement program for the modern computing environment-Olex2 dissected. Acta Crystallogr. A71 (2015) 59-75.

4. Dolomanov, O. V.; Bourhis, L. J.; Gildea, R. J.; Howard, J. A. K.; Puschmann, H.: OLEX2: a complete structure solution, refinement and analysis program. J. Appl. Crystallogr. 42 (2009) 339-341.

5. Liu, Y.-L.; Zou, P.; Xie, M.-H.; Luo, S.-N.; He, Y.-J.: Ethyl 3-carboxy-5-nitrobenzoate. Acta Crystallogr. E65 (2009) 01174.

6. Luo, Y.-H.; Pan, M.-L.: 4-Nitroisophthalic acid. Acta Crystallogr. E68 (2012) 0206

7. Saleh, M. I.; Tham, W.-T.; Adnan, R.; Kusrini, E.; Ng, S.L.; Fun, H.-K.: A second orthorhombic polymorph of 5nitroisophthalic acid monohydrate. Acta Crystallogr. E62 (2006) 04837-04839.

8. Domenicano, A.; Schultz, G.; Hargittai, I.; Colapietro, M.; Portalone, G.; George, P.; Bock, C. W.: Molecular structure of nitrobenzene in the planar and orthogonal conformations. Struct. Chem. 1 (1990) 107-122.

9. Xu, Z.; Yang, H.; Cheng, G.: Studies on the synthesis and properties of polynitro compounds based on esteryl backbones. New J. Chem. 40 (2016) 9936-9944 